\title{
FORMULASI MASKER GEL ANTIOKSIDAN MENGANDUNG EKSTRAK KULIT BUAH NAGA MERAH (Hylocereus polyrhizus)
}

\author{
Sunarmi, Susilo Yulianto \\ Kementerian Kesehatan Politeknik Kesehatan Surakarta Jurusan Jamu
}

\begin{abstract}
Antioxidant, Red Dragon Fruit, Gel Mask. Skin is an organ that covers the entire human body, which has protection against external influences. Free radicals and the oxidation reaction can be inhibited by an antioxidant compound. Red dragon fruit peel is rarely used, but has high antioxidant activity that can be used for skin care, especially facial skin. Red dragon fruit peel can be formulated into various dosage form of antioxidants for the face skin, one of which peel-off mask gel. This study aimed to test the antioxidant activity of peel-off mask gel with the active ingredient of red dragon fruit peel extracts. This research uses experimental methods. Red dragon fruit peel extracted by maceration in 70\% ethanol and concentrated. Gel mask made in 3 variations extract concentration, ie formula $A, B$ and $C 0.175 \mathrm{~g}, 0.350 \mathrm{~g}$ and $0,700 \mathrm{~g}$ respectively. Physical stability test was conducted by cycling test for 6 cycles. The physical properties of the preparation was tested before and after storage include adhesion, dispersive power, $\mathrm{pH}$, viscosity and time to dry. Antioxidant activity tested with DPPH method. Based on test results obtained physical stability, third-formula gel mask physically qualified and stable, except for the dispersive power. Antioxidant activity decreased after the storage. The highest activity was shown by the formula $C$ with $I C_{50}$ value of 3497.113 ppm. Based on IC $I_{50}$ values, this gel mask has an inactive.antioxidant activity.
\end{abstract}

Keyword: Antioxidant, Red Dragon Fruit, Gel Mask

Abstrak: Antioksidan, Buah Naga Merah, Masker Gel. Kulit adalah organ yang menutupi seluruh tubuh manusia, yang memiliki perlindungan terhadap pengaruh eksternal. Radikal bebas dan reaksi oksidasi dapat dihambat oleh senyawa antioksidan. Kulit buah naga merah jarang digunakan, namun memiliki aktivitas antioksidan tinggi yang bisa digunakan untuk perawatan kulit, terutama kulit wajah. Kulit buah naga merah bisa diformulasikan menjadi berbagai bentuk sediaan antioksidan untuk kulit wajah, salah satunya adalah lapisan topeng kupas. Penelitian ini bertujuan untuk menguji aktivitas antioksidan gel topeng peel-off dengan bahan aktif ekstrak kulit buah naga merah. Penelitian ini menggunakan metode eksperimen. Kulit buah naga merah diekstraksi dengan maserasi dalam etanol $70 \%$ dan terkonsentrasi. Masker gel dibuat dalam 3 variasi konsentrasi ekstrak, yaitu formula A, B dan C $0.175 \mathrm{~g}, 0,350 \mathrm{~g}$ dan 0,700 g masing-masing. Uji stabilitas fisik dilakukan dengan uji bersepeda selama 6 siklus. Sifat fisik sediaan diuji sebelum dan sesudah penyimpanan meliputi adhesi, daya dispersif, $\mathrm{pH}$, viskositas dan waktu kering. Aktivitas antioksidan diuji dengan metode DPPH. Berdasarkan hasil uji didapatkan stabilitas fisik, topeng gel formula ketiga secara fisik mumpuni dan stabil, kecuali untuk daya dispersif. Aktivitas antioksidan menurun setelah penyimpanan. Aktivitas tertinggi ditunjukkan dengan rumus $\mathrm{C}$ dengan 
nilai IC50 sebesar 3497.113 ppm. Berdasarkan nilai IC50, masker gel ini memiliki aktivitas anti aktif.

Kata Kunci: Antioksidan, Buah Naga Merah, Masker Gel

\section{PENDAHULUAN}

Kulit merupakan organ yang menutupi seluruh tubuh manusia, dan mempunyai daya proteksi terhadap pengaruh luar. Kulit sangat mendukung penampilan seseorang sehingga perlu dirawat, dipelihara, dan dijaga kesehatannya. Dengan perawatan dan pemeliharaan, maka penampilan kulit akan terlihat sehat, terawat, serta senantiasa memancarkan kesegaran (Wirajayakusuma, 1998). Radikal bebas merupakan molekul yang relatif tidak stabil, memiliki elektron yang tidak berpasangan di orbital luarnya sehingga bersifat reaktif dalam mencari pasangan elektron. Radikal bebas yang berlebihan menyebabkan antioksidan seluler tidak dapat menetralkannya sehingga berakibat pada kerusakan sel (Inayah, 2006). Radikal bebas dan reaksi oksidasi dapat dihambat oleh suatu senyawa antioksidan. Antioksidan dapat menunda, memperlambat, dan bisa menjadi molekul-molekul yang mampu menetralkan efek oksidasi (Pangkahila, 2007). Antioksidan dapat diperoleh dari makanan sehari-hari seperti sayuran, buah-buahan, kacang-kacangan dan tanaman lainnya yang mengandung senyawa antioksidan bervitamin (seperti vitamin $\mathrm{C}$, vitamin $\mathrm{A}$, dan vitamin $\mathrm{E}$ ), asam-asam fenolat (seperti asam ferulat, asam klorogerat, asam elagat dan asam kafeat) dan senyawa flavonoid (Sinaga, 1996).

Buah naga merah termasuk dalam famili Cactaceae, memiliki rasa yang manis dan segar. Keunggulan dari kulit buah naga yaitu kaya polifenol dan merupakan sumber antioksidan (Wu ,et al, 2006). Aktivitas antioksidan pada kulit buah naga lebih besar dibandingkan aktivitas antioksidan pada daging buahnya, sehingga berpotensi untuk dikembangkan menjadi sumber antioksidan alami. Pada buah naga merah, aktivitas antioksidan kulit lebih besar dibandingkan daging buahnya, dimana kulit buah naga merah memiliki aktivitas antioksidan sebesar $83,48 \%$ dengan $\mathrm{IC}_{50}$ sebesar 0,30 mg/mL (Nurliyana, 2010). Buah naga memiliki aktifitas antioksidan yang kuat secara in vitro, sehingga bisa memungkinkan untuk digunakan sebagai suplemen makanan ataupun sediaan farmasi (Khalili et al, 2012).

Saat ini belum ditemukan adanya formula sediaan antioksidan kulit dari kulit buah naga merah. Salah satu bentuk sediaan yang dapat dibuat adalah masker gel peel off yang dapat diaplikasikan untuk kulit wajah. Sediaan gel dipilih karena mempunyai efek pendinginan pada kulit saat digunakan, penampilan sediaan yang jernih dan elegan, pada kulit setelah kering meninggalkan film tembus pandang, elastis dan mudah dicuci dengan air, pelepasan obat dan penyebarannya pada kulit baik.

Berdasarkan hal tersebut di atas, maka peneliti tertarik melakukan penelitian berupa formulasi masker gel peel off antioksidan dengan bahan aktif ekstrak kulit buah naga merah dan diuji aktivitas antioksidan dengan metode DPPH. 


\section{METODE PENELITIAN}

Penelitian ini menggunakan rancangan penelitian eksperimental. Kulit buah naga merah dibuat ekstrak kental dan dibuat formula masker gel peel off. Sediaan masker gel diuji stabilitas fisiknya dengan metode cycling test 6 siklus. Parameter yang diamati pada penelitian ini berupa parameter fisik gel meliputi $\mathrm{PH}$, viskositas, $\mathrm{pH}$, waktu mengering, daya sebar dan stabilitas, serta aktivitas antioksidan gel.

\section{HASIL PENELITIAN \\ Ekstrak kulit buah naga merah}

Ekstraksi kulit buah naga merah menggunakan metode maserasi etanol $70 \%$ dengan perbandingan sampel dan pelarut 1:1 diperoleh hasil ekstrak kental berwarna coklat, lengket, dan berbau manis khas kulit buah naga. Dari jumlah kulit buah naga merah basah sebanyak $1650 \mathrm{~g}$ diperoleh jumlah ekstrak sebanyak $35,82 \mathrm{~g}$, sehingga rendemen yang dihasilkan sebanyak 2,17 \%. Hasil uji aktivitas antioksidan ekstrak kulit buah naga merah dengan metode DPPH didapatkan penghitungan prosentase inhibisi dan konsentrasi didapatkan persamaan $\mathrm{y}=0.0252 \mathrm{x}+5.9277$, dan dengan perhitungan diperoleh nilai $\mathrm{IC}_{50}$ sebesar 1748,901 ppm.

\section{Masker Gel Peel Off}

Masker gel peel off kulit buah naga merah yang dihasilkan berwarna bening pada formula A, dan krem pada formula B dan C. Sediaan untuk ketiga formula memiliki bentuk semi padat, berbau khas kulit buah naga merah dan tercampur rata atau homogen. Setelah dilakukan uji stabilitas menunjukkan tidak terjadi perubahan organoleptik pada semua formula. Sediaan masker gel terdapat pada Gambar 1.

Hasil uji fisik sediaan diperoleh nilai $\mathrm{pH}$ cenderung mengalami penurunan seiring dengan penambahan konsentrasi ekstrak. Nilai $\mathrm{pH}$ sediaan setelah dilakukan penyimpanan cenderung turun pada formula $A$, namun meningkat pada formula $\mathrm{B}$ dan $\mathrm{C}$. $\mathrm{pH}$ semua sediaan sebelum dan sesudah penyimpanan masih dalam rentang normal sediaan untuk kulit yakni antara 4,5-6,5. Sediaan gel diuji daya sebarnya untuk mengetahui sejauh mana gel dapat merata saat diaplikasikan padakulit. Berdasarkan uji daya sebar untuk ketiga formula menunjukkan adanya penurunan daya sebar seiring dengan peningkatan konsentrasi ekstrak. Setelah dilakukan penyimpanan, daya sebar gel cenderung turun pada formula $\mathrm{A}$ dan $\mathrm{B}$, namun terjadi peningkatan daya sebar pada formula $\mathrm{C}$.

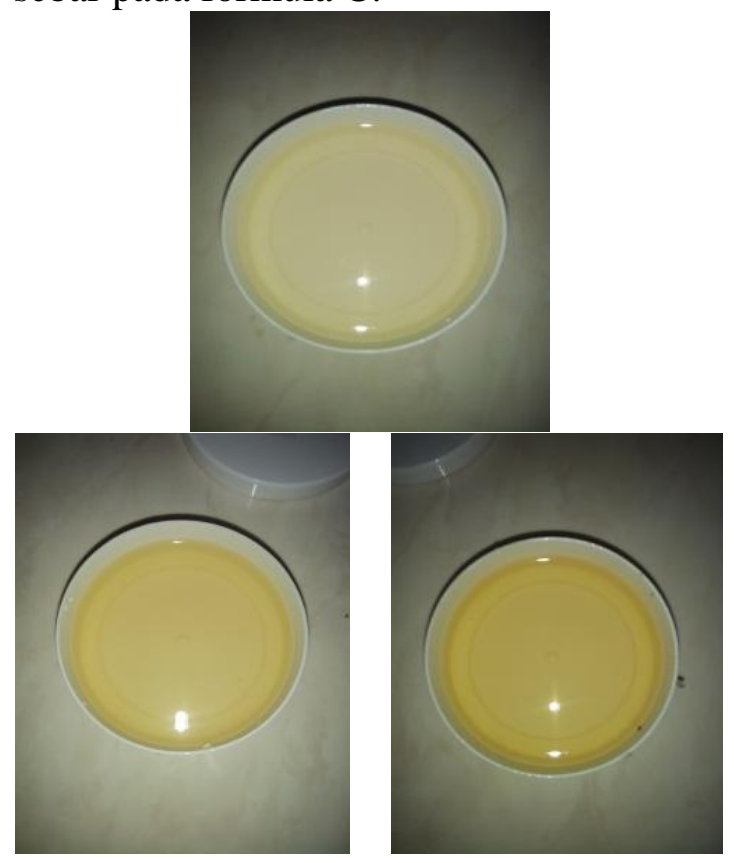

Gambar 1. Sediaan Masker gel Peel Off Formula A, B, dan C 
Daya lekat gel cenderung meningkat sesuai dengan peningkatan konsentrasi ekstrak. Kecenderungan peningkatan daya lekat setelah penimpanan terjadi pada formula $\mathrm{A}$ dan $\mathrm{B}$, namun cenderung menurun pada formula C. Viskositas sediaan masker gel cenderung meningkat seiring peningkatan konsentrasi ekstrak. Setelah penyimpanan terjadi peningkatan kekentalan pada formula A dan B, namun terjadi penurunan pada formula $\mathrm{C}$. Meskipun terdapat perbedaan viskositas dan perubahan setelah penyimpanan, namun nilai viskositas ketiga formula memenuhi syarat viskositas sediaan gel.

Waktu mengering sediaan paling lama ditunjukkan oleh formula $\mathrm{C}$, sedangkan waktu mengering tercepat ditunjukkan oleh formula A. Berdasarkan hasil uji stabilitas, terjadi perubahan waktu mengering lebih cepat pada formula A dan lebih lama pada formula C, sedangkan pada formula B tidak terjadi perubahan waktu mengering. Sifat fisik sediaan sebelum dan sesudah penyimpanan terdapat pada tabel 1 .

\section{Tabel 1}

Sifat Fisik Masker Gel Peel Off Ekstrak Kulit Buah Naga Merah

\begin{tabular}{cccccc}
\hline \multirow{2}{*}{ Formula } & \multicolumn{2}{c}{$\begin{array}{c}\text { Daya Sebar } \\
(\mathbf{c m})\end{array}$} & \multicolumn{2}{c}{$\begin{array}{c}\text { Waktu } \\
\text { mengering } \\
\text { (Menit) }\end{array}$} & $\mathbf{p}$ \\
\cline { 2 - 6 } & $\mathbf{X}_{\mathbf{1}}$ & $\mathbf{X}_{\mathbf{2}}$ & $\mathbf{X}_{\mathbf{1}}$ & $\mathbf{X}_{\mathbf{2}}$ & $\mathbf{X}_{\mathbf{1}}$ \\
\hline A & 8,20 & 8,20 & 21 & 19 & 5.61 \\
B & 7,86 & 7,86 & 23 & 23 & 5.52 \\
C & 6,20 & 6,20 & 26 & 27 & 5.13 \\
\hline
\end{tabular}

Ket: $\mathrm{X}_{1}$ : sebelum penyimpanan, $\mathrm{X}_{2}$ : sesudah penyimpanan

Aktivitas antioksidan sediaan masker gel ekstrak kulit buah naga merah diuji dengan metode DPPH. Aktivitas antioksidan masker gel ekstrak kulit buah naga dinyatakan dengan $\mathrm{IC}_{50} . \mathrm{IC}_{50}$ sediaan masker gel sebelum penyimpanan berturut-turut dari formula $\mathrm{A}, \mathrm{B}$, dan $\mathrm{C}$ sebesar 3011,17 ppm, 2710,81 ppm, dan 2699,99 ppm. Setelah dilakukan uji stabilitas dengan metode cycling test 6 siklus didapatkan nilai $\mathrm{IC}_{50}$ formula $\mathrm{A}, \mathrm{B}$, dan $C$ sebesar 4773,54 ppm, 3881,11 ppm, dan 3497,11 ppm. Berdasarkan hal tersebut, nilai $\mathrm{IC}_{50}$ paling rendah ditunjukkan oleh formula $\mathrm{C}$, meskipun berdasarkan kategorinya termasuk antioksidan lemah. Proses penyimpanan menunjukkan terjadinya penurunan aktivitas antioksidan yang ditunjukkan dengan adanya peningkatan nilai $\mathrm{IC}_{50}$. Proses penyimpanan menurunkan aktivitas antioksidan dilihat dari kenailan nilai $\mathrm{IC}_{50}$ pada formula A sebesar 58,53, Formula B 43,17\%, dan formula C $29,52 \%$.

\section{PEMBAHASAN}

Ekstrak kulit buah naga merah yang diperoleh berwarna coklat pekat tidak sesuai dengan penelitian Penelitian Putri dkk (2015) mendapatkan ekstrak kulit buah naga merah berwarna merah pekat. Kulit buah naga merah mengandung pigmen antosianin yang memberikan warna merah siskositosianin pظersifat tidaktiktabil apabilaps dipanaskan, namm akan lebih stabil apabila dalam suXsana Xsam. Ekstrak Kulit butah naga

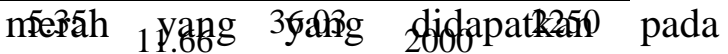
penelitian ini berwarna coklat karena pada

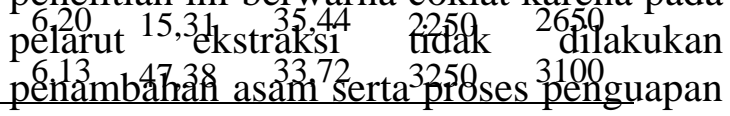
ekstrak dilakukan dengan pemanasan pada suhu $\pm 60^{\circ} \mathrm{C}$ di dalam waterbath dalam waktu yang lama sehingga memungkinkan warna merah dari antosianin menjadi pudar. 
Jumlah rendemen ekstrak kulit buah naga merah pada penelitian ini sebesar $2,17 \%$. Jumlah rendemen tersebut berbeda dengan hasil penelitian Khalili et al (2012) yang menyatakan ektrak kulit buah naga merah memiliki rendemen sebesar 10,65 \pm $1,08 \%$. Perbedaan jumlah rendemen tersebut dipengaruhi oleh tempat tumbuh tanaman, kadar air sampel, jenis dan kemurnian pelarut, metode dan lama ekstraksi. Semakin lama ekstraksi dilakukan akan lebih banyak senyawa yang bisa diambil sehingga meningkatkan jumlah rendemen.

Antioksidan dikategorikan menjadi 2, yaitu primer dan sekunder. antioksidan primer bekerja dengan menangkap radikal bebas dengan mendonorkan atom hidrogen atau elektron sehingga merubahnya menjadi bentuk yang stabil. Uji DPPH digunakan untuk menguji antioksidan primer (Nurliyana et al, 2010).

Aktivitas antioksidan kuit buah naga merah dikarenakan adanya kandungan antosianin dan betasianin yang merupakan antioksidan kuat(Putri dkk, 2015; Rebecca, 2010).

Uji aktivitas antioksidan ekstrak kulit buah naga merah dengan metode DPPH menunjukkan nilai $\mathrm{IC}_{50}$ sebesar 1748,901 ppm. Berdasarkan uji DPPH, aktivitas antioksidan ekstrak kulit buah naga merah pada penelitian ini dikategorikan lemah. Turunnya nilai aktivitas antioksidan tersebut kemungkinan dikarenakan rusaknya komponen fenol yang terdapat pada kulit buah naga merah karena adanya pemanasan. Aktivitas antioksidan tersebut tidak sesuai dengan penelitian sebelumnya yang menunjukkan nilai $\mathrm{IC}_{50}$ kulit buah naga merah sebesar 73,2772 ppm (Putri dkk, 2015), serta Hui et al (2014) yang menunjukkan nilai $\mathrm{IC}_{50}$ sebesar 0,83 $\mathrm{mg} / \mathrm{ml}$ atau $830 \mathrm{ppm}$.

Formula masker gel peel off kulit buah naga merah diuji sifat fisik dan stabilitasnya menggunakan metode cycling test. Uji stabilitas dilakukan untuk menilai ketahanan sediaan masker gel terhadap waktu penyimpanan dan perubahan suhu lingkungan.

Masker gel pada saat pembuatan memiliki warna bening yang semakin meningkat menjadi krem bening sesuai penambahan konsentrasi ekstrak, dan memiliki bau khas kulit buah naga merah, homogen, berbentuk semi padat dan terasa dingin saat diaplikasikan di kulit. Setelah dilakukan penyimpanan tidak terjadi perubahan organoleptik pada semua formula.

Tingkat keasaam sediaan dilakukan dengan mengukur $\mathrm{pH}$, dan didapatkan nilai $\mathrm{pH}$ masker gel peel off kulit buah naga merah untuk formula $\mathrm{A}$, B, dan $C$ berturut-turut 5,61, 5,52, dan 5,13. Nilai $\mathrm{pH}$ cenderung lebih rendah seiring dengan penambahan konsentrasi ekstrak. Nilai $\mathrm{pH}$ sediaan setelah dilakukan penyimpanan cenderung turun pada formula $\mathrm{A}$, namun meningkat pada formula $\mathrm{B}$ dan $\mathrm{C}$. $\mathrm{pH}$ tertinggi ditunjukkan oleh formula $\mathrm{B}$, yakni sebesar 6,20, dan $\mathrm{pH}$ terendan terdapat pada formula A sebesar 5,13. Nilai $\mathrm{pH}$ sediaan topikal tidak boleh terlalu asam karena dapat menyebabkan iritasi dan tidak boleh terlalu basa karena dapat menyebabkan kulit bersisik. Nilai $\mathrm{pH}$ semua sediaan sebelum dan sesudah penyimpanan masih dalam rentang normal sediaan untuk kulit yakni antara 4,5 - 6,5. Perubahan $\mathrm{pH}$ ketiga formula setelah penyimpanan secara umum tidak terlalu signifikan sehingga dapat dikatakan sediaan gel memiliki $\mathrm{pH}$ yang relatif stabil. 
Uji daya sebar dilakukan untuk mengetahui sejauh mana kemampuan gel untuk dapat menyebar saat diaplikasikan pada kulit. Daya sebar sediaan gel saat awal berturut-turut untuk formula A, B, dan $C$ sebesar $8,2 \mathrm{~cm}, 7,86 \mathrm{~cm}$, dan 6,2 $\mathrm{cm}$. Setelah penyimpanan terjadi perubahan nilai daya sebar gel untuk formula A, B, dan $\mathrm{C}$ berturut-turut menjadi $7,71 \mathrm{~cm}, 7,81 \mathrm{~cm}$, dan $7,76 \mathrm{~cm}$. Menurut Garg et al (2002), daya sebar gel yang baik antara $5-7 \mathrm{~cm}$. Berdasarkan hal tersebut, formula A dan B tidak memenuhi syarat daya sebar gel, dan hanya formula $\mathrm{C}$ yang memenuhi syarat. Penyimpanan yang dilakukan merubah daya sebar gel, yakni meningkat pada formula $\mathrm{C}$ dan turunpada formula $\mathrm{A}$ dan B. Daya sebar gel untuk ketiga formula setelah dilakukan penyimpanan tetap tidak memenuhi syarat daya sebar gel.

Meskipun formula C awalnya memenuhi syarat namun setelah dilakukan penyimpanan terjadi perubahan daya sebar, sehingga dikatakan tidakstabil. Daya sebar gel dipengaruhi oleh kuatnya ikatan matriks gel atau gelling agent. matriks gel yang berikatan kuat akan menyebabkan gel sulit menyebar, dan ikatan matriks yang kurang kuat menyebabkan gel menjadi cenderung lebih mudah menyebar.

Pengujian daya lekat dilakukan untuk mengetahui kemampuan sediaan gel mampu melekat pada kulit setelah diaplikasikan Hasil pengujian daya lekat gel formula $\mathrm{A}, \mathrm{B}$, dan $\mathrm{C}$ pada awal pembuatan berturut turut sebesar 11,66 detik, 15,31 detik dan 47,38 detik. dari data tersebut diketahui daya lekat gel cenderung meningkat sesuai dengan peningkatan konsentrasi ekstrak. Daya lekat gel setelah penyimpanan mengalami perubahan, dimana daya lekat formula $\mathrm{A}$
36,03 detik, formula B 35,44 detik, dan formula C 33,72 detik. Dari data tersebut diketahui terjadi perubahan daya lekat pada semua formula, dimana pada formula A dan B daya lekat semakin meningkat, namun cenderung menurun pada formula C.

Daya lekat yang baik dari sediaan semipadat adalah lebih dari 1 detik (Zats dan Gregory, 1996 dalam Nugraha, 2012). Semakin tinggi daya lekat gel, maka waktu yang memungkinkan gel untuk kontak dengan permukaan kulit lebih lama, sehingga memungkinkan gel bekerja lebih optimal. Berdasarkan hasil pengujian sebelum dan sesudah penyimpanan menunjukkan bahwa terjadi perubahan daya sebar gel namun masih memenuhi syarat yang ditetapkan.

Uji viskositas sediaan gel formula A 2000 cps, formula B $2250 \mathrm{cps}$, dan formula C 3250 cps. Berdasarkan hal tersebut terjadi peningkatan viskositas gel seiring peningkatan jumlah ekstrak. Peningkatan viskositas gel berkaitan dengan meningkatnya jumlah ekstrak, dimana peningkatan ekstrak mengakibatkan tolakmenolak antar gugus karboksil yang menyebabkan terjadinya penurunan jumlah gugus karboksil yang berikatan sehingga pengembangan struktur carbopol menurun (Sari dan Isadiartuti (2006). Viskositas suatu sediaan dipengaruhi oleh beberapa faktor, antara lain faktor pencampuran atau pengadukan saat pembuatan sediaan, pemilihan zat pengental dan surfaktan (Ansel, 1989).

Viskositas gel setelah penyimpanan mengalami peningkayan, yakni menjadi 2250 cps pada formula A, 2650 cps pada formula B dan 3100 cps pada formula C. Kenaikan viskositas selama penyimpanan kemungkinan terjadi karena ada penguapan sediaan gel selama 
penyimpanan. Meskipun terjadi perubahan viskositas, namun sediaan gel di awal maupun setelah penyimpanan masih memenuhi syarat viskositas gel yakni $2000-4000$ cps.

Waktu mengering sediaan masker gel peel off ekstrak kulit buah naga merah sebelum penyimpanan untuk formula $\mathrm{A}$, B, dan $\mathrm{C}$ berturut-turut 21, 23, dan 26 menit. Waktu mengering paling lama ditunjukkan oleh formula $\mathrm{C}$, sedangkan waktu mengering tercepat ditunjukkan oleh formula A. Setelah dilakukan didapatkan waktu mengering untuk formula $\mathrm{A}, \mathrm{B}$, dan $\mathrm{C}$ berturut-turut 19, 23, dan 27 menit. Berdasarkan hasil uji stabilitas, terjadi perubahan waktu mengering lebih cepat pada formula A dan lebih lama pada formula $\mathrm{C}$, sedangkan pada formula B tidak terjadi perubahan waktu mengering.

Masker gel peel off idealnya mengering dalam waktu 15 - 30 menit. Berdasarkan data di atas, dapat dikatakan sediaan gel untuk ketiga formula memenuhi syarat waktu mengering yang ideal. Lamanya waktu mengering menunjukkan bahwa air pada sediaan tersebut mampu terlepas ke dalam kulit dan pada waktu yang samazat aktuf mampu memberikan efeknya (Zhelsiana dkk, 2016). Waktu mengering yang paling cepat cenderung lebih baik karena lebih cepat memberikan efek yang diinginkan. Sehingga formula A dikatakan memiliki waktu mengering yang paling baik di antara formula yang lain.

Aktivitas antioksidan masker gel peel off kulit buah naga merah pada formula A, B, dan C sebesar 3011,17 ppm, 2710,81 ppm, dan 2699,99 ppm cenderung semakin kuat seiring dengan penambahan konsentrasi ekstrak. Hal tersebut sesuai dengan penelitian Hui et al
(2014) dan Ibrani (2010) yang menyebutkan bahwa aktivitas antioksidan semakin meningkat sesuai peningkatan dosis (atau konsentrasi) eksrak. Aktivitas antioksidan sediaan mengalami penurunan setelah dilakukan cycling test yang diketahui dari peningkatan nilai $\mathrm{IC}_{50}$ untuk formula A, B, dan C, yakni 4773,54 ppm, 3881,11 ppm, dan 3497,11 ppm. Penurunan aktivitas antioksidan masker gel setelah penyimpanan kemungkinan disebabkan oleh karena pengaruh perubahan sudu, dimana suhu yang tinggi memungkinkan gel mengalami oksidasi sehingga menurunkan aktivitas antioksidannya (Ibrani, 2010).

\section{KESIMPULAN DAN SARAN}

Masker gel peel off ekstrak kulit buah naga merah memenuhi syarat fisik gel dan stabil secara fisik meliputi organoleptik, $\mathrm{pH}$, daya lekat, daya sebar dan waktu mengering, namun tidak memenuhi syarat daya sebar gel. Aktivitas antioksidan masker gel meningkat seiring peningkatan konsentrasi ekstrak dan mengalami penurunan aktivitas setelah penyimpanan, namun dikategorikan aktivitas atioksidannya tidak aktif. Oleh karena itu perlu dilakukan metode ekstraksi kulit buah naga merah yang tepat agar menghasilkan ekstrak yang memiliki aktivitas antioksidan yang kuat. Selain itu perlu penggunaan bahan tambahan yang tepat agar menghasilkan sediaan gel yang memenuhi syarat fisik serta memiliki efek antioksidan yang baik

\section{DAFTAR RUJUKAN}

Ansel, H.C. (1989). Pengantar bentuk sediaan farmasi, edisi keempat, terjemahan Ibrahim dan farida. Jakarta: Universitas Indonesia Press. 
Garg A, et al. (2002). Spreading of semisolid formulation. An update, Pharmacetical Technology.

Hui L, Yongqiang C, Zhijun P, Tao L, and Shengjie Y (2014) Chemical composition and in vitro evaluation of the cytotoxic and antioxidant activities of supercritical carbon dioxide extracts of pitaya (dragon fruit) peel Chemistry Central Journal 2014, 8:1

Ibrani, MF. (2012). Aktivitas antioksidan dan stabilitas fisik gel anti-aging yang mengandung ekstrak etanol ubi jalar ungu (Ipomoea batatas L.). Universitas Indonesia, Skripsi.

Khalili MA, Abdullah AB, Manaf A (2012) Total antioxidant activity, total phenolic content and radical scavenging activity both flesh and peel of red pitaya, white pitaya and papaya. Int J Pharm Pharm Sci, 4 (2): $113-122$

Nurliyana, R, Zahir, I S, Suleiman, K M, Aisyah, MR, dan Rahim, K K,
2010 Antioxidant study of pulps and peels of dragon fruits: a comparative study International Food Research Journal, 17 : 367365

Pangkahila, W (2007) Anti aging medicine:memperlambat penuaan, meningkatkan kualitas hidup Jakarta: PT Kompas Media Nusantara, 13-19

Rebecca OPS, Boyce AN, and Chandran S, (2010) Pigment identification and antioxidant properties of red dragon fruit (Hylocereus polyrhizus) African Journal of Biotechnology, 9(10): 1450-1454

Wu, L C, Hsu, H W, Chen, Y, Chiu, C C, and Ho, Y I, 2006, Antioxidant and Antiproliferative Activities of Red Pitaya, Food Chemistry Volume, $95: 319-327$

Zhelsiana, D.A. (2016). Formulasi dan evaluasi sifat fisik masker gel peel off lempung bentonite. The 4th University Coloquium: $42-45$. 